\title{
Microvascular Angiopathic Consequences of COVID-19
}

\author{
Margaret Nalugo ${ }^{1}$, Linda Schulte ${ }^{1}$, Muhammad Faraz Masood ${ }^{2}$, and Mohamed Zayed ${ }^{1}$ \\ ${ }^{1}$ Washington University in St Louis School of Medicine \\ ${ }^{2}$ Washington University in Saint Louis School of Medicine
}

November 18, 2020

\begin{abstract}
The coronavirus disease-2019 (COVID-19) pandemic has rapidly spread across the world. The disease is caused by severe acute respiratory syndrome coronavirus 2 (SARS-CoV-2), which first appeared in Wuhan, China in December, 2019. Ever increasing data is emerging about COVID-19 and its effects on the arterial and venous circulation. Clinical features associated with COVID-19 suggest that endothelial cell dysfunction and microvascular thrombosis are to a large part contributing to resultant multi-organ complications. This review is aimed at highlighting the critical aspects associated with COVID-19 and its presumed microvascular angiopathic complications leading to multi-organ dysfunction.
\end{abstract}

\section{Hosted file}

Zayed_COVID Microvascular Angiopathy_11-16-2020.pdf available at https://authorea.com/users/ 376693/articles/493598-microvascular-angiopathic-consequences-of-covid-19

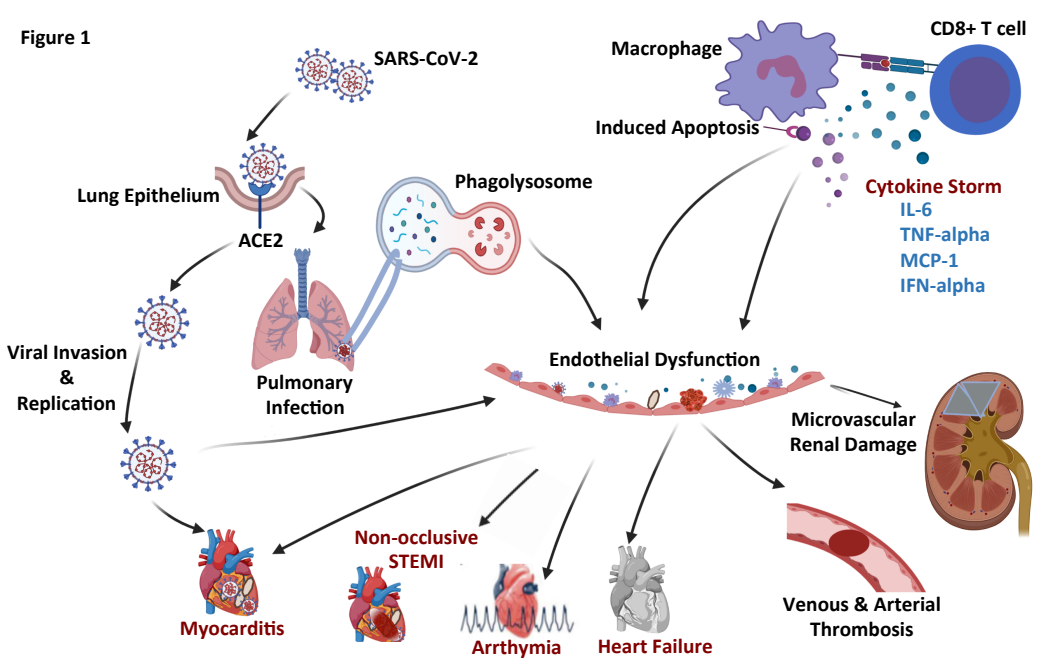




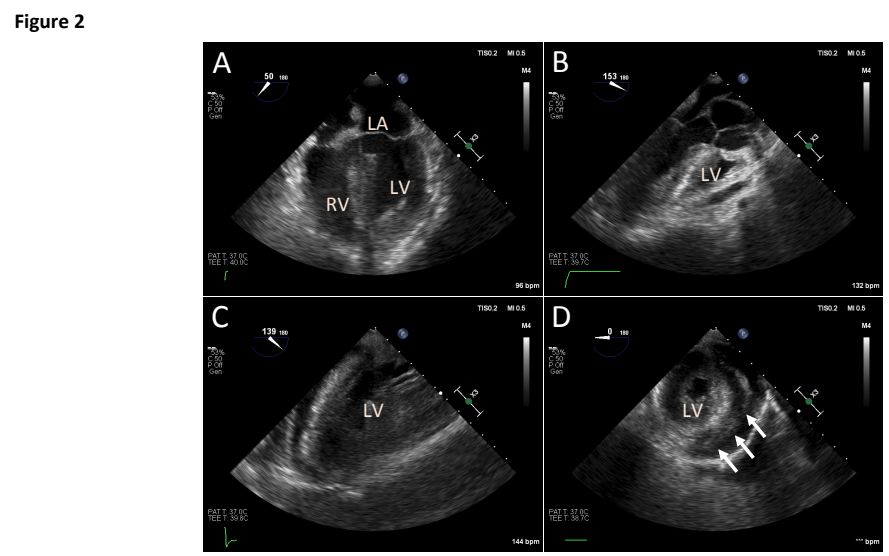

Figure 3
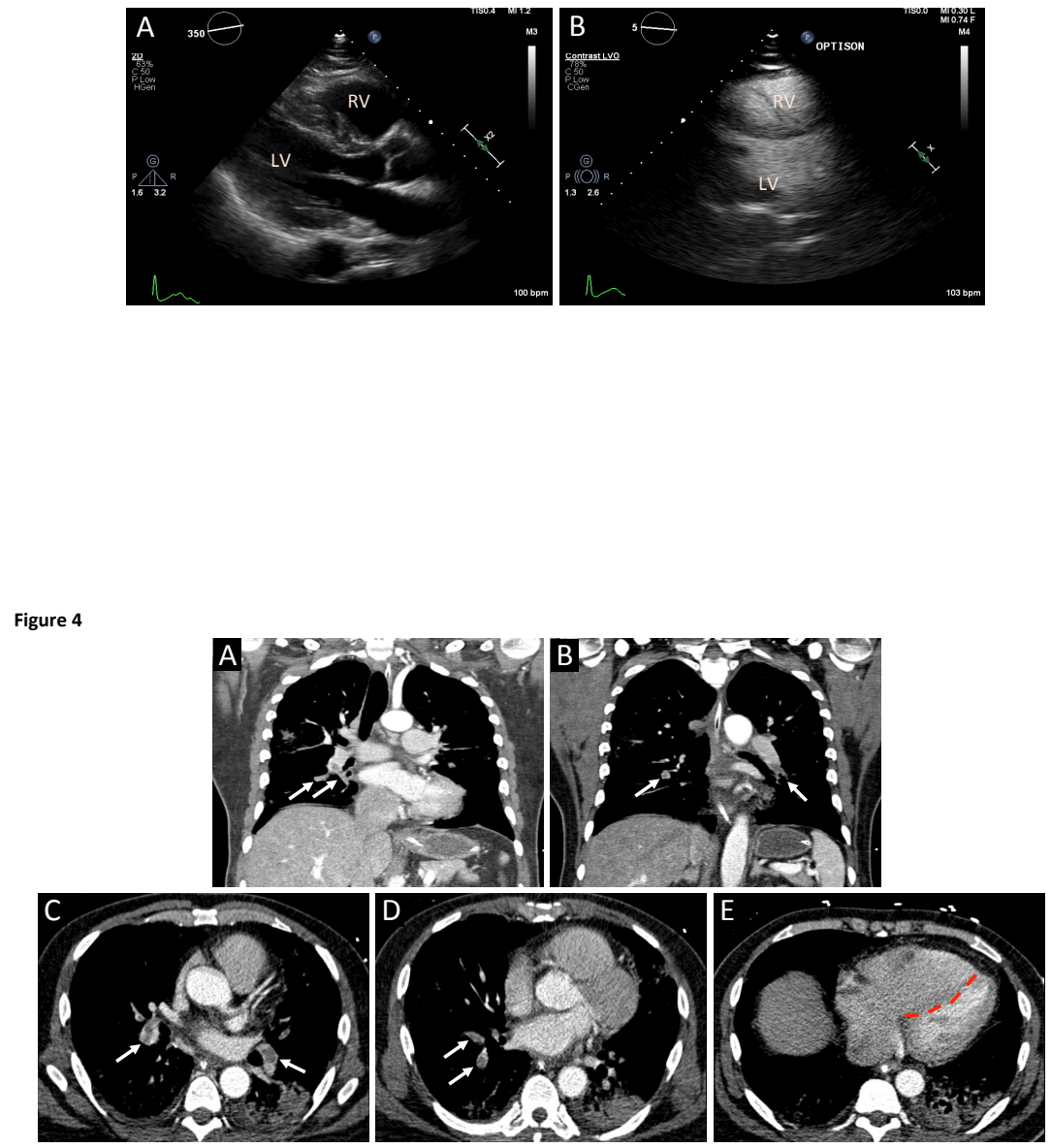